\title{
On the Importance of Art Theory in Art Education
}

\author{
Yi Wen \\ Northwestern University, Xi'an, Shaanxi,China
}

\begin{abstract}
Key words: Art theory, Art education, Importance
\end{abstract}
\begin{abstract}
With the continuous completion of Chinese educational system, teaching course content of higher education has been increasingly richer and people's philosophy of receiving education is also increasingly stronger. In order to respond to the nation's call of developing comprehensive education, some universities have added basic courses of art educations one after another. Some parents send their children to professional art training classes for professional training and some students sign up for art academies in college entrance examination to realize their art dreams. Art theory courses are the basic links of art education. Only by laying solid basis can one realize his dreams of art. This paper explains the importance of art theory in art education from the perspectives of the content of art theory and learning art theories.

Art theory is the most basic and most critical teaching content in art education. To primary art students, art theory is especially important. It can provide valuable technical guidance to students. At present, many art academies pursue the improvement of students' art techniques excessively in art education without realizing the importance of art theory and such unbalanced education viewpoints and educational methods go against students' comprehensive development. Valuing the teaching of art theory and "engaging in idle theorizing" are never the same. In art education process, the teaching goal of valuing professional theory courses is to keep the balanced status between technique course teaching and theoretical class teaching so that every student can obtain comprehensive development in professional art education.
\end{abstract}

\section{Concept of art theory}

Definition of art theory. At present, many art academies pursue the improvement of students' art techniques excessively in art education without realizing the importance of art theory and such unbalanced education viewpoints and educational methods go against students' comprehensive development. Valuing the teaching of art theory and "engaging in idle theorizing" are never the same.

From the perspective of the essence of aesthetics, most artists believe that art theories are practical summaries of people in the creation process of art forms. Generally speaking, people's generalized understanding of art theory includes art history, art basic theory, artistic aesthetics and artistic criticism. However, to academic field, the narrow category is usually adopted, which means that art theory refers to basic theories of art. Basic theories of art take art works creation and art works appreciation as research objects and are integrated into natural real life. When they are studying art theories (including discussion on the essence and characteristics of art), they are also studying sociology, psychology and art philosophy.

Development history of Chinese art theory. In earlier stages of art theory development, there was no systemic art knowledge system or concept of art theory, and there were only viewpoints of art creation, which became the predecessor of art theory. China has 5000 years of historical civilization and art developed every early. As early as Shang and Zhou dynasties, painting types which took lacquer painting as art forms had appeared. With the emergence of characters, some viewpoints on art were also documented in literatures. The pre-Qin period was the most glorious period in Chinese cultural academic history, in which the prosperous scene of "contention of a hundred schools of thought" was formed. Art theory development under this background. "Painting after simplicity" "unrestrained painting" and "dogs and horses are the most difficult to be painted" were the earliest record of art theories. They not only have guidance significance on art painting, but also have rich philosophical thoughts. When it came to the Period of Wei, Jin and Southern and 
Northern Dynasties, systemic art theories appeared in China, such as Gu Kaizhi's "vivid expression" and "great result comes from free imagination", Chen Yaozui's "feeling nature's rules with heart" and Xie He's "six rules". When it came to Tang Dynasty, the calligrapher and painter Zhang Yanyuan summarized the previous painting techniques and proposed "the unity between poem and painting”. When it came to Song and Yuan Dynasty, Su Shi, Zhao Meng, etc. proposed the theory of scholars' painting. In Ming and Qing Dynasty, the number of works about art theories reached over 2000 and most of them were summaries of previous art theories. In the last century, Qi Baishi, Zhang Daqian, Li Keran and other well-known artists expanded the field of traditional art theory.

\section{Differences of domestic and foreign art theory researches}

Because of different cultural background, Chinese art theory has distinct sear of Chinese civilization. It is very different from foreign art theory in the following aspect:

Different theoretical forms. As to the form of art theories, Chinese art theory is not entirely different from that of the West. Chinese art theory pays attention to the perceptibility and experience of works. It mainly studies aesthetics, artistic evaluation of specific works as well as the creator's subjective and objective world. It mainly involves the creator's creation style and the subject's personality. While Western art theory values more abstract analysis of the works, therefore, Western art theory usually presents strong logic.

Different theoretical core. Chinese traditional paintings pay attention to the expression of freehand brushwork. Chinese traditional art theory praises moderation, harmony and unity and emphasizes "combination of virtulity and reality", "combination of art and forms" and "hardness with softness". In a painting, they unify and restrict each other in the composition, forming the dialectal relationship of unity of opposites. Chinese traditional art theory has rich humanistic tastes and the sense of art is especially strong. Foreign art theories were developed on the commanding height of science and they like using scientific perspective as the basis of art creation. Foreign art theory has richer content. They would use chromatics, art anatomy, perspective science and other disciplinary theories in art creation. In addition, foreign art theory values description of details and they create art works like producing confidential instruments.

Different social values. From the significance of sociology, Chinese traditional art theory describes general yearning and pursuit for harmonious society through expression of the relationship between human and nature and human and human. Chinese art theories are inseparable from the nation's traditional culture's integration of art intension. Therefore, Chinese art theoretical center is valuing the social functions of art. Different from Chinese art theories, Western art theories pay more attention to the formal beauty of the works and they emphasize non-interest and non-utilitarian property of art. What should be mentioned is that with the development of time, globalization has been accelerated and Chinese and Western cultures have been influencing, penetrating, integrating and absorbing each other, which is inevitable. However, the national character of Chinese art theories will never change.

\section{Problems in Chinese art theory research}

At the beginning of the 20th century, many educated youth went abroad with the idea of "national salvation". It was just in that period that the word of "art" entered China; in the meantime, it opened up the gate of researches of Chinese modern art theory. However, because of influences of political elements in that period, from the beginning of the foundation of New China to reform and opening up policy, art theory researches were forced to end. Until the 1980s, art theory researches were resumed. Therefore, in real sense, there has only been 30 years for Chinese researches of modern art theory. At present, the following problems exist in researches of Chinese modern art theories:

Lack of Chinese traditional art theory researches. Impacts of modern life lead to more and more obvious cultural influences. In the meantime, development trend of culture turns to integration 
gradually. Faced with the "invasion" of Western culture, development of Chinese traditional culture was obstructed seriously. It is the same with art theory researches. Since people generally believe foreign countries are better than China, it is the same situation in art theory researches. At present, there are countless books, periodicals and academic theses of art theory researches. However, most of them are about Western art theories and very rare are about Chinese traditional art theories. In addition, painting art exhibitions of various scales are inundated with Western-style works, such as oil painting, watercolor, gouache, etc. and there is almost no Chinese traditional ink painting or bird-and-flower painting. This is not to negate Western art theories, but that we cannot put too much emphasis on foreign art theory researches in the process of art theory researches. We should increase researches of Chinese traditional art theories, which is also beneficial to the protection of Chinese traditional culture.

Low quality of translation works. Modern art theories come from the West. In order to obtain better art theory researches, we usually adopt translation methods and the most representative one is Development History of Art translated by Fan Jingzhong. The original author of the book is Gombrich, a British aesthetician. The book has detailed explanation of Western art theories and art creation thoughts. However, not every translated work is as excellent as Development History of Art. It is mainly represented in the following aspects: firstly, inaccurate orientation of professional terms. Art has developed to a systemic academic discipline up to now and art theory involves large quantities of professional terms. Because of cultural differences, many terms cannot be described in Chinese and they lack corresponding terms. Many translators just adopt self-creation method, which results to inaccurate orientation of professional terms. Secondly, vague technical layer. At present, many translated works of art theory are not completed by artists. Most of the translators are proficient in foreign languages but they lack art basis. Many translators begin the translation without understanding, which results to misreading in technical and academic layer.

\section{The importance of art theory in art education}

Conductive to students' comprehensive improvement. Many people's understanding of art theory teaching is over one-sided and they believe that art theory teaching only involves professional knowledge of art; actually, the content of art theory teaching is very rich. It not only involves the relationship between art and society and art and humans, but also psychology and philosophy. Art theory teaching aims to make students become more comprehensively high-quality talent on the basis of cultivating art. Through art theory teaching, students can not only learn professional knowledge of art, but also improve their outlook on life and values.

Conductive to the improvement of students' painting techniques. Art theory is cultural knowledge part and painting technique belongs to the category of practice. There is dialectical relationship between art theory and art painting techniques. Painting techniques are the basis of art theory, and all art theories are extracted from painting techniques. If there are no painting techniques, there would be no art theory. However, painting techniques must have art theory as theoretical guidance. Only on the premise of understanding art theories can one improve his painting techniques. During the process of learning art, art theory can help students form art creation philosophy; later, students can practice their painting techniques according to art theories.

Conductive to strengthen the subsidiary role of art education in common course teaching. At present, in the art education common course teaching process of Chinese higher education, a new art interdisciplinary subject was born, i.e., utilizing various artistic expressions for art psychotherapy and painting therapy is the main content. As early as the middle period of last century, utilizing painting aesthetics for middle intervention of some pathological diseases has emerged in some Western countries. For example, promising effects have been made in treating mental disease. In this century, painting therapy has developed rapidly no matter in China or overseas countries and it has been applied in psychological consulting and therapy. Indeed, we are not encouraging students at art to go to hospitals to treat patients after learning it, but it is an undisputable fact that it has become a boundary science of art major. Art theory has promoted the 
development of art education common course teaching and the formation of more and more interdisciplinary sciences of art. It has penetrated into people’s daily life comprehensively.

Conclusion: At present, as to the general trend of Chinese art education, art theory has not attracted enough attention in art education practice. As to the evaluation construction of credits, scores of art theory take up too little in the overall scores. In addition, many problems exist in art theory teaching philosophy and teaching methods, which all need us to solve. With the development of art education career and the continuous improvement of people's artistic aesthetic standard, the importance of art theory will be improved gradually in art education.

\section{References:}

[1] J. Liang; Several Problems in Current Art Theory and Creation [N]; China Culture Daily; 2008 (In Chinese)

[2] J. Liang; Several Problems in Current Art Theory and Creation [N]; China Culture Daily; 2008 (In Chinese)

[3] L.Z. Zhao\& B.L. Jiang; QingQuanXiXin. Ma Shuoshan Academic Seminar of Chinese Painting Works [N]; China Art Weekly; 2010 (In Chinese) 